\title{
The Current Status of Medical Education Reform and Medical Goal Deviation
}

\author{
Jin-guo WANG ${ }^{1, a}$ and Na WANG ${ }^{2, b,{ }^{*}}$ \\ ${ }^{1}$ Department of Urology, the First Hospital of Jilin University, China \\ ${ }^{2}$ Department of Anesthesiology, the First Hospital of Jilin University, China \\ awangjinguolily@163.com, bwangna080613@163.com \\ ${ }^{*}$ Corresponding author
}

Keywords: Medical education, Reform, Medical goal, Development.

\begin{abstract}
Along with the rapid development of society and economy and the new problems in health care system, traditional medical purpose has been challenged and the new purpose of modern medical science has formed. New medical purpose includes preventing illness and injury, promoting and maintaining health, avoiding and releasing pain associated with diseases, caring of patients who have poor prognosis and providing hospice care. Medical education reform must be adapted to the new medical purpose to improve the quality of medical students.
\end{abstract}

\section{Introduction}

Health promotion and disease prevention is the core of the medical value. As is known to all, illness and injury can be prevented, and the doctor's most basic responsibility is to help patients and education of the patients, doctors to help patients to prevent disease is more important than the treatment of disease. The child mortality in the world today has been very high, it is particularly important to health promotion. Reduce the incidence of undoubtedly conducive to economic development, directly reduce the medical expenses of high and new technology. From the medical profession, the understanding of medicine is more than just "save disease cure", as a guard the most important part of service system [1].

\section{The Challenge of the Traditional Medical Purpose}

\section{The Traditional Medicine Only Takes Patients as Carriers of Diseases}

The traditional medicine ignores the patient as a whole, ignores the combination of social and psychological factors. The doctor is always a leading role, the patient is always supporting role.

\section{Traditional Medicine Focuses on Treatment, Not Prevention}

People measure the development of medicine and the level of an important standard is to see it found that the ability of disease, diagnosis of diseases, as well as through medical understanding of disease, development of the corresponding to the treatment of diseases and prevention method, finally achieve the goal of conquest and eliminate diseases. The medical from initial behavior as a result, the end has not left the disease. This narrow, one-sided understanding of the purpose of medicine and disease centered concept, cause of disease under long-term technical rule medicine, cause of the contemporary world health crisis. It is also directly contributing to the social health care 
system, mechanism, the development direction of medical, some deviation on the direction of medical education [2].

\section{The Aim of the Traditional Medicine is Too Perfect to Realize}

The aim of the traditional medicine is the pursuit to maintain perfect person's physical, psychological and social status. But this is just a beautiful wish, simply cannot achieve completely, because the person's life from birth to the normal death through various stages, each stage has different standard of health, inevitably accompanied by a variety of chronic disease until death.

\section{New Medical Purpose}

\section{Medical Treatment and Health Care is One System}

Renew ideas first asked the doctor to set up the new Chinese health not only refers to the absence of disease and pain on the body, but also to have a sound physical and mental status and social adaptation ability. Second asked the doctor to clearly recognize the medicine is not only a clinical disease, the purpose of access to health, more important is to prevent disease health promotion [3].

\section{Patient-centered is the Core of the New Medical Purpose}

Also, the doctor of your future responsibilities: doctors should promote health, prevention and treatment of diseases, to provide primary health care, physicians were keen to heal and relieve the pain, the doctor also should be good health work management personnel, patients and communities, excellent diplomat, have created thinker, publicity, social science and behavioral science knowledge mentor and strive to the scholars of lifelong learning.

It is not conducive to competition in the market. In recent years, the pharmaceutical companies are increasing spending on research and development of traditional Chinese medicine, improve the protection of traditional Chinese medicine, promote the competitiveness of the enterprise market. Therefore, traditional Chinese medicine patent applications to ascend. As such, it is suggested that scientific research institutes, colleges and universities and industrial and mining enterprises of traditional Chinese medicine research and development input, enhance the consciousness of intellectual property protection of traditional Chinese medicine, promote the traditional Chinese medicine scientific achievements into productivity, to accelerate the process of internationalization of Chinese medicine.

\section{Specific Content of the New Medical Purpose}

\section{Preventing Illness and Injury and Promoting and Maintaining Health}

The purpose of learning is not only a clinical disease, prevent disease and promote health, medical workers service object is not only the patients in the hospital, and community and rural health group, so the employment direction of medical students is not only into the hospital make a diagnosis and give treatment disease and nursing care of patients, and out of the hospital, Michael people in community and rural health education and publicity, to the public advocate healthy way of life, health concept, health behavior, the popularization of medical knowledge, improve the self health care consciousness of the masses [4]. 


\section{Avoiding and Alleviating Pain}

Some chronic diseases such as hypertension symptom is not obvious, patients seeking care measures to alleviate the symptoms, some alleviate psychological pressure. Pain and suffering in the patient's body there are both connection and difference. Pain physiological changes, often reflected in the psychological pain and pressure. Pain relief is also one of the ancient traditional medicine target. Modern medicine in palliative care medicine has arisen. Doctor people-oriented, care for the patient, relieve mental suffering and anxiety [5]. According to statistics half the patients feel pain, but there is no objective physical changes, only require a doctor's care and care. Also this category is for psychiatric treatment.

\section{Caring the Patient with Poor Prognosis}

Found medical seeking the cause, diagnosis evidence, in order to cure the patient returned to normal, the patient not only need treatment also need sympathy and care. While traditional medical treatment function, despise care for function, it is wrong. Medical cure function includes two aspects of treatment and care for. With more attention paid to the rehabilitation medicine in modern medicine, some cases can fully recover function; some only recover part of refund changes such as rehabilitation. In an aging society, chronic disease is a common cause of pain, suffering and death, that is to say the disease care will accompany one's life. Patient education, therefore, learn to self care ability, long-term struggle with chronic disease is one of the doctor's responsibility [6]. In a sense medicine is not only a medicine, but also care for medicine.

\section{Improvement of Hospice Care}

Symptoms and death struggle is one of the important goals of medicine, but medicine is to accept the normal end facts of life. A sense, the medical basic responsibility is to help the healthy growth of young people, to help the elderly health life, until the humanitarian concern. The development of modern medical science has made human life expectancy increased [7].

It can promote invention patent, the invention can promote the tremendous progress in medicine. In a market economy environment, the hospital is facing fierce competition, competition, the key depends on the core competitiveness patent is the core competitiveness of a powerful symbol. So hospitals in our country the status of the patent by this article, based on the comparative analysis of domestic hospital industry patents, the advantages and disadvantages in trying to predict the future the trend of the development of the hospital industry patent.

\section{Summary}

To sum up, four specific objectives constitute medicine in the new goals, content is rich, and embodies the "people-oriented, to the patient as the center" concept, reflects the prevention health care as one of the goals.

\section{References}

[1] Brieger G H. Why the university-based medical school should survive: a historical perspective. Academic medicine: journal of the Association of American Medical Colleges. 1997

[2] Cohen J, Dannefer EF, Seidel HM, Weisman CS, Wexler P, Brown TM, Brieger GH, Margolis S, Ross LR, Kunitz SJ. Medical education change: a detailed study of six medical schools. Medical Education. 1994 
[3] McParland Monica, Noble Lorraine M, Livingston Gill. The effectiveness of problem-based learning compared to traditional teaching in undergraduate psychiatry. Medical Education. 2004

[4] Qirard Y, Kondo M, Yoshizawa K. The Journal of Chemical Physics. 2006

[5] Karyn D. Baum, Sara Axtell. Trends in North American medical education. The Keio Journal of Medicine. 2005

[6] Mc Parland M, Noble LM, Livingston G. The effectiveness of problem-based learningcompared to traditional teaching in undergraduate psychiatry. Med Edu. 2004

[7] Roger Brown. Quality Assurance In Higher Education-The UK experience since1992. 2004 